\title{
Synthesis and Characterization of Nitrosonaphthol Dyes Based on 1-Naphthol and Their Dyeing Properties on Tanned Leather
}

\author{
Umar Salami Ameuru*, Mohammed Kabir Yakubu, Kasali Ademola Bello \\ Department of Textile Science and Technology, Ahmadu Bello University, Zaria, Nigeria \\ Email: ${ }^{\text {ameuru umar@yahoo.com }}$
}

Received 31 March 2014; revised 6 May 2014; accepted 13 May 2014

Copyright (C) 2014 by authors and Scientific Research Publishing Inc.

This work is licensed under the Creative Commons Attribution International License (CC BY). http://creativecommons.org/licenses/by/4.0/

(c) (i) Open Access

\begin{abstract}
Nitrosonaphthol dyes and other corresponding analogues were synthesised from 1-Naphthol. The dyes were applied onto chrome and vegetable tanned leather upon characterization. The results indicate that the dye bath exhaustion was better on chrome tanned leather than on vegetable tanned leather. This may be attributed to the chelating effect of chrome on leather and the higher temperature of dyeing the chrome tanned leather compared with the vegetable tanned leather. The fastness properties of the dyes of washing ranging from (3 - 5), perspiration on acid (4 - 5), alkaline (4 - 5) and light (4 - 7) were impressive on both vegetable and chrome tanned leather respectively.
\end{abstract}

\section{Keywords}

2-Nitroso-1-Naphthol, Tanned Leather, Exhaustion, Fastness

\section{Introduction}

Leather is dyed to improve its appearance and make it saleable in a finished form. Some colours may be imparted by the tanning agent, but usually this is supplemented with synthetic dyes and/or pigments. Leather dyes are selected by the dyer on the bases of hue, application properties (solubility, levelness, and penetration), fastness properties (light, water, perspiration, rubbing, solvents) and tinctorial strength-cost factor [1].

Today leather is mostly used for shoes, upholstery, clothing, gloves, bookbinding, handbags, soles and work

*Corresponding author.

How to cite this paper: Ameuru, U.S., et al. (2014) Synthesis and Characterization of Nitrosonaphthol Dyes Based on 1-Naphthol and Their Dyeing Properties on Tanned Leather. Open Journal of Applied Sciences, 4, 354-359.

http://dx.doi.org/10.4236/ojapps.2014.46032 
protection, or orthopedic purposes. At consumer level, the outstanding stability of leather and its colour ensure a long service life for leather goods. The important leather dyes identified by typical chemical nomenclature are azo, stilbene, triarylmethane, quindine, azine, oxazine, thiazine, sulfur and phthalocyanine [2].

In this work, nitrosonaphthol dyes have been found to be suitable for dyeing tanned leather by exhaustion process due to the presence of nitroso-hydroxyl compounds that are an example of a system that possess an intramolecular hydrogen bond. They are the key regents in the production of azo dyes. Since they are good chelating agent [3], they have found a place in many analytical [4], synthetics [5] and other applications [6] [7]. In solution, nitrosonaphthols as well as nitrosophenols generally exist in tautomeric equilbria with the corresponding quinine-monoxime forms (Figure 1). The syntehsized dyestuff and intermediate compounds were verified by using mass spectra, FT-IR and UV-visible spectra. Wash, light and perspiration fastness properties on the tanned leathers are also studied.

\section{Experimental}

All the chemicals used in the synthesis of the intermediates and dyes were of analytical grade and were used without purification. Melting points were determined by Gallen Kamp apparatus. The visible absorption spectra were measured using Thermo Spectronic UV—visible He $\lambda$ ios spectrophotometer. IR spectra were recorded on a Nicolet IR Model 100 spectrophotometer and the Mass spectra were determined on an GC/MS _ DIP Mass spectrometer.

\section{Synthesis of 2-Nitroso-1-Naphthol (1)}

1-Naphthol, (49.96 g) was dissolved in $500 \mathrm{~cm}^{3}$ of distilled water containing $13.30 \mathrm{~g}$ sodium hydroxide at room temperature while vigorously stirring the solution with magnetic stirrer $140 \mathrm{~cm}^{3}$ of ethanoic acid was added drop wise. Solution of $\mathrm{NaNO}_{2}$ was added over an hour using the separating funnel to the fine suspension produced. A greenish yellow precipitate produced was washed several times with distilled water until a clear golden yellow residue was obtained and dried in oven at $60^{\circ} \mathrm{C}$ until constant weight was obtained. The melting point was determined using Gallen kamp apparatus [8].

Synthesis of 4-[(E)-(4-hydroxy-3-nitrosonaphthalen-1-yl)diazenyl]benzoic acid (2)

4-amino benzoic acid (1.37 g), was dissolved in $10 \mathrm{~cm}^{3}$ of distilled water contained in a beaker equipped with a mechanical stirrer and standing in an ice bath. 0.025 mole of $\mathrm{HCl}$ acid was added. The temperature of the amine dispersion was maintained at $0^{\circ} \mathrm{C}-5^{\circ} \mathrm{C}$ using an ice slurry. $50 \mathrm{~cm}^{3}$ solution of $\mathrm{NaNO}_{2}$ was then added drop wise for 30 minutes. The solution obtained was kept at $0^{\circ} \mathrm{C}-5^{\circ} \mathrm{C}$ for a period of 45 minutes to achieve compete diazotization. The diazonium salt was coupled with 2-nitroso-1-naphthol to produced dye structure 2, as shown in Figure 2.

Synthesis of 4-[(E)-(4-nitrophenyl)diazenyl]-2-nitrosonaphthalen-1-ol (3)

4-nitroaniline diazotization was done by suspension method. 4-nitroaniline (1.38 g), was dissolved in 0.025 mls of hot concentrated $\mathrm{HCl}$, while Standing in an ice bath solution of $\mathrm{NaNO}_{2}$ was added over 30 minutes. The solution was stirred for a further 45 minutes and coupled with 2-nitroso-1-naphthol to produced dye (3) as shown in Figure 2.

Synthesis of 4-[(E)-(4-methoxyphenyl)diazenyl]-2-nitrosonaphthalen-1-ol (4)

P-methyloxyaniline $(1.38 \mathrm{~g}$ ) was dissolved in $0.025 \mathrm{mls}$ of hot concentrated $\mathrm{HCl}$, while standing in an ice bath solution of $\mathrm{NaNO}_{2}$ was added over 30 minutes. The solution was stirred for a further 45 minutes and coupled with 2-nitroso-1-naphthol to produced dye (4) as shown in Figure 2.

Synthesis of 4-[(E)-(4-hydroxy-3-nitrosonaphthalen-1-yl)diazenyl] benzenesulfonic acid (5)

Sulphanilic acid $(1.31 \mathrm{~g})$ was dissolved in $50 \mathrm{ml}$ of distilled water containing $0.4 \mathrm{~g}$ of $\mathrm{NaOH} .50 \mathrm{~g}$ of crushed<smiles>C=C=C=Nc1ccc2ccccc2c1O</smiles><smiles>O=C1/C(=N\O)C=Cc2ccccc21</smiles>

Figure 1. Nitrosonaphthol/quinine-monooxime tautomeric equilibra. 




Figure 2. Structure of intermediate and dyes produced.

ice was added into the beaker standing in an ice bath. The diazonium salts produced was then added gradually to the well stirred solution of 2-nitroso-1-naphthol over 30 minutes. The reaction was allowed to proceed for 1 hour to produced dyes (5) as shown in Figure 2.

Synthesis of 4-[(E)-(4-hydroxyphenyl)diazenyl]-2-nitrosonaphthalen-1-ol(6)

4-aminophenol (1.09 g) was dissolved in 50 mls of distilled water containing $0.4 \mathrm{~g}$ of NaOH. $50 \mathrm{~g}$ of crushed ice was added into the beaker standing in an ice bath. The diazonium salts produced was then added gradually to the well stirred solution of 2-nitroso-1-naphthol over 30 minutes. The reaction was allowed to proceed for 1 hour to produced dyes (2) as shown in Figure 2.

Synthesis of 5-hydroxy-6-[(E)-(4-hydroxy-3-nitrosonaphthalen-1-yl)diazenyl] naphthalene-2-sulfonic acid (7)

2-amino-8-hydroxynaphthalene-6-sulphonic acid ( $\gamma$-acid) (2.07 g) was dissolved in $50 \mathrm{ml}$ of distilled water containing $0.4 \mathrm{~g}$ of $\mathrm{NaOH}$. $50 \mathrm{~g}$ of crushed ice was added into the beaker standing in an ice bath. The diazonium salts produced was then added gradually to the well stirred solution of 2-nitroso-1-naphthol over 30 minutes. The reaction was allowed to proceed for 1 hour to produced dyes (7) as shown in Figure 2.

Synthesis of 3-hydroxy-4-[(E)-(4-hydroxy-3-nitrosonaphthalen-1-yl)diazenyl] naphthalene-1-sulfonic acid (8) 
4-amino-3-hydroxynaphthalene-1-sulphonic acid (2.07 g) was dissolved in $50 \mathrm{ml}$ of distilled water containing $0.4 \mathrm{~g}$ of $\mathrm{NaOH} .50 \mathrm{~g}$ of crushed ice was added into the beaker standing in an ice bath. The diazonium salts produced was then added gradually to the well stirred solution of 2-nitroso-1-naphthol over 30 minutes. The reaction was allowed to proceed for 1 hour to produced dyes (8) as shown in Figure 2.

\subsection{Application of Synthesized Dyes on Vegetable and Chrome Tanned Leather}

About $4.00 \mathrm{~g}$ of both vegetable and chrome tanned leather were dyed with $1 \%$ dye shade respectively. The $\mathrm{pH}$ of the dyebath was adjusted by adding $0.1 \%$ of formic acid. The temperature of dyeing was $40^{\circ} \mathrm{C} \pm 2^{\circ} \mathrm{C}$ and $50^{\circ} \mathrm{C} \pm$ $2^{\circ} \mathrm{C}$ for vegetable and chrome tanned leather respectively. The liquor to goods ratio of 20:1 was used.

\subsection{Determination of Wash, Light and Perspiration Fastness}

The wash, light and perspiration fastness were carried out according to ISO I, ISO 105 and ISO104 respectively [9].

\section{Results and Discussion}

The identified mass spectrometer of 2-nitroso-1-naphthol (1) with mass-to-charge ratio (m/e) of 30, 39, 51, 63, $75,101,128,143,156$ and the parent total of 173 which represent the molecular weight (M) of 2-nitroso-1naphthol. The corresponding positive charged fragment of $\mathrm{NO}^{+}, \mathrm{C}_{3} \mathrm{H}_{3}^{+}, \mathrm{C}_{4} \mathrm{H}_{3}^{+}, \mathrm{C}_{5} \mathrm{H}_{3}^{+}, \mathrm{M}_{-} \mathrm{C}_{4} \mathrm{H}_{3} \mathrm{O}_{2} \mathrm{~N}, \mathrm{M}-$ $\mathrm{C}_{3} \mathrm{H}_{2} \mathrm{O}_{2} \mathrm{~N}, \mathrm{M}-\mathrm{C}_{2} \mathrm{NO}_{2} \mathrm{H}, \mathrm{M}-\mathrm{OHON}, \mathrm{M}-\mathrm{NO}, \mathrm{M}-\mathrm{OH}$ were obtained.

As presented in Table 1, all the compounds showed absorption in the visible region greater or equal to 400 $\mathrm{nm}$ which were characteristics of all the compounds studied. The tinctorial strengths for the dyes were good as indicated by the extinction coefficients being greater than $200,001 \mathrm{~mol}^{-1} \cdot \mathrm{cm}^{-1}$ [10]. The percentage exhaustion of both the vegetable tanned leather and chrome tanned leather was observed to be good but chrome tanned leather gave very good result which may be attributed to the chelating of the chrome on the leather and the high temperature of dyeing chrome tanned leather. In Table 1, the selected frequencies peaks for the dye are shown. $\mathrm{OH}$ stretching vibration bands appeared in the region of $3747-3188 \mathrm{~cm}^{-1}$ for the dyes. $\mathrm{CH}$ stretching vibration bands appeared in the region of $3090-2831 \mathrm{~cm}^{-1}$ for the dyes. N=N stretching vibration bands appeared in the region of $1430-1595 \mathrm{~cm}^{-1}$ for the dyes. $\mathrm{COOH}$ stretching vibration bands appeared in the region of $1685-1792$ $\mathrm{cm}^{-1}$ for the dyes. $\mathrm{N}=\mathrm{O}$ stretching vibration bands appeared in the region of $1436-1559 \mathrm{~cm}^{-1}$ for the dyes. $\mathrm{NO}_{2}$ stretching vibration bands appeared in the region of $1332 \mathrm{~cm}^{-1}$ for the dyes. $\mathrm{SO}_{3} \mathrm{H}$ stretching vibration bands appeared in the region of $1101-1256 \mathrm{~cm}^{-1}$ for the dyes. $\mathrm{OCH}_{3}$ stretching vibration bands appeared in the region

Table 1. FTIR, Yield, Melting Point and UV-visible spectroscopic properties of the dyes.

\begin{tabular}{|c|c|c|c|c|c|}
\hline \multirow{2}{*}{ Dye No. } & \multirow{2}{*}{ Yield (\%) } & \multirow{2}{*}{ Melt pt. $\left({ }^{\circ} \mathrm{C}\right)$} & \multicolumn{2}{|c|}{ UV-visible Spectroscopy } & \multirow{2}{*}{ Selected frequency } \\
\hline & & & $\lambda_{\max }(\mathrm{nm})$ & $\varepsilon \times 10^{4}\left(\mathrm{~mol}^{-1} \cdot \mathrm{cm}^{-1}\right)$ & \\
\hline 1 & 60.7 & 138 & 500 & 4.9729 & $\begin{array}{l}\text { OH 3747, 3245: -C-H 3090, 2972, } \\
\text { 2853: -N=N- 1550, 1587: -COOH } \\
\text { 1792, 1665: -N=O } 1550\end{array}$ \\
\hline 2 & 77.9 & $170-172$ & 420 & 3.9418 & $\begin{array}{l}\text { OH 3744: -C-H 3087, 2969, } 2853 \\
\text {-N=N- 1442: -N=O 1559. }\end{array}$ \\
\hline 3 & 40.9 & 152 & 505 & 5.4242 & $\begin{array}{l}\text { OH 3739, 3235: -C-H 2969, 2854: } \\
-\mathrm{N}=\mathrm{N}-1552,1587:-\mathrm{N}=\mathrm{O} 1552: \\
-\mathrm{SO}_{3} \mathrm{H} 1101,1142 .\end{array}$ \\
\hline 4 & 88.5 & $129-131$ & 425 & 4.5970 & $\begin{array}{l}\text { OH 3188: -C-H 3078, 2968: -N=N- } \\
\text { 1589: -N=O 1514: }-\mathrm{NO}_{2} 1332 . \\
\text { OH 3745, 3244: -C-H 3090, 2972: }\end{array}$ \\
\hline 5 & 85.1 & $152-153$ & 440 & 4.4910 & $\begin{array}{l}-\mathrm{N}=\mathrm{N}-1551,1589:-\mathrm{N}=\mathrm{O} 1551: \\
-\mathrm{SO}_{3} \mathrm{H} 1139,1231 .\end{array}$ \\
\hline 6 & 83.0 & $117-119$ & 415 & 4.1549 & $\begin{array}{l}\text { OH 3616, 3367: -C-H 3068: -N=O } \\
\text { 1458, 1509: -OCH } 2840,2941 . \\
\text { OH 3724, 3244: -C-H 3090, 2972: }\end{array}$ \\
\hline 7 & 59.0 & $147-149$ & 510 & 5.1206 & $\begin{array}{l}-\mathrm{N}=\mathrm{N}-1553,1587:-\mathrm{N}=\mathrm{O} 1434: \\
-\mathrm{SO}_{3} \mathrm{H} \text { 1142, } 1232 .\end{array}$ \\
\hline 8 & 85.0 & $146-148$ & 560 & 2.8139 & $\begin{array}{l}\text { OH 3204: -C-H 3083: -N=O 1436, } \\
1561\end{array}$ \\
\hline
\end{tabular}


of $2840-2941 \mathrm{~cm}^{-1}$ for the dyes [11]. These indicate the presence of all the functional groups in the synthesized dyes.

The resistance of dyed materials to laundry treatment such as washing is referred to as wash fastness. This is of great importance to the consumer, and there are several washing tests that are applied according to the purpose for which the material is intended. In the present research, ISO wash test NO. 1 procedure was adopted. As shown in Table 2, it was observed that the wash fastness is generally good with little staining of adjacent white fabric. For instance, the scale rating is good to very good for dyes 1 - 5 and 6 - 8 (i.e. 3 - 4) in vegetable tanned leather. The scale rating of very good was observed in chrome tanned leather for dyes 1 - 8 (i.e. 4 - 5) with little staining of adjacent white fabric.

It was observed that the monosulphonated dyes (3), (6) and (7) gave good to very good wash fastness. This is quite in line with the observation that affinity of dyes for fibre molecules tends to reduce the rate of transport of dyes into or out of the substrate. The strength of the dye fibre molecules aims to cause the dyes molecules to remain attached to fibre molecules rather than to diffuse along the pores of the fibre [12]. It is also in agreement with the general assessment that the fewer the sulphonated groups that are there in a dye molecule the more slowly it desorbs into alkaline solution and the more of such groups are present the rapid is the desorption.

The good wash fastness observed of dyes (1), (2), (4) and (5) may be attributed to the substituents such as $-\mathrm{COOH}$ and $-\mathrm{OH}$ in dyes (1) and (2) and $-\mathrm{NO}_{2}$ and $-\mathrm{OCH}_{3}$ in dyes (4) and (5) respectively.

Light fastness is the resistance of colour of dyed materials to the influence of light. The fastness assessment can be done using daylight for a long period or by a xenon arc, which is the accelerated version of the test [12]. In the present study, for achieving quick result, the xenon arc test was employed and the evaluation of results was based on the eight wool standard 1 to 8 . As indicated in Table 2, both vegetable tanned leather and chrome tanned leather generally showed good light fastness ranging from 4 to 7 , vegetable tanned leather gives better results than chrome tanned leather.

The light fastness ratings of the dyes on tanned leather indicated that for the monosulphonated dyes (3), (6) and (7) gave very good ratings which are in line with the fact that the lower the sulphonic acid groups, the better are the photo-stability; Evan had investigated this in details. They explained that the number of sulphonic acid group affects photo-stability from the point of view of surface activity in relation to aggregation state [13]. Dyes (1) and (2) contain amino group and hydroxyl group which are hydrogen bonded onto the azo linkage. This double hydrogen bonding prevents the tautomerism that is normally a feature of naphthalene base azo dyes by locking in the azo form, leading to the high level of light fastness. The same phenomena can be used to explain the good light fastness ratings of dyes (4) and (5) coupled with the presence of $\mathrm{NO}_{2}$ and $\mathrm{OCH}_{3}$ in dyes (4) and (5) respectively.

Perspiration measures the resistance of dyed substrate to body fluids when in use especially areas where these fluids are prominent. Test to acidic and alkaline perspiration media have been carried out. The results were assessed on change of shade using grey scale ratings as well as degree of staining of the adjacent white fabric similar to the wash fastness; the results are also shown in Table 2.

Table 2. Fastness properties of vegetable and chrome tanned leather.

\begin{tabular}{|c|c|c|c|c|c|c|c|c|}
\hline \multirow{3}{*}{ Dyes No. } & \multicolumn{4}{|c|}{ Vegetable tanned leather } & \multicolumn{4}{|c|}{ Chrome tanned leather } \\
\hline & \multirow[t]{2}{*}{ Wash } & \multirow[t]{2}{*}{ Light } & \multicolumn{2}{|c|}{ Perspiration } & \multirow[t]{2}{*}{ Wash } & \multirow[t]{2}{*}{ Light } & \multicolumn{2}{|c|}{ Perspiration } \\
\hline & & & Acid & Alkaline & & & Acid & Alkaline \\
\hline 1 & 4 & 7 & $4-5$ & $4-5$ & 4 & 4 & $4-5$ & 4 \\
\hline 2 & $3-4$ & 7 & 4 & $4-5$ & 4 & 5 & $4-5$ & $4-5$ \\
\hline 3 & $3-4$ & $6-7$ & $4-5$ & 4 & 4 & $4-5$ & $4-5$ & $4-5$ \\
\hline 4 & 4 & 6 & $4-5$ & 4 & 4 & $6-7$ & 5 & $4-5$ \\
\hline 5 & 3 & $4-5$ & 4 & $2-3$ & 4 & 4 & 5 & $2-3$ \\
\hline 6 & 3 & 7 & $4-5$ & $4-5$ & $3-4$ & $5-6$ & $4-5$ & $4-5$ \\
\hline 7 & 3 & 6 & $4-5$ & $4-5$ & 4 & 6 & 5 & 4 \\
\hline 8 & $4-5$ & 6 & $4-5$ & $4-5$ & $4-5$ & 6 & 5 & 4 \\
\hline
\end{tabular}


The fastness to perspiration was generally good both in acidic and alkaline media but fair results were observed in the case of dye 5 in alkaline medium in vegetable tanned leather and chrome tanned leather respectively. However, it was observed that the acidic ratings are higher than the alkaline ratings. This observation, could be attributed to the repulsion between the anionic sulphonated group and anionic charge sites in the fibre, a negative affinity is produced in alkaline medium as opposed to the acidic medium condition where there is positive affinity of sulphonated groups for cation site in the fibre which will by analogy produce superior fastness properties than the alkaline medium condition [14].

\section{Conclusion}

2-nitroso-1-naphthol was used as coupling components to synthesized azo dyes using several aromatic amines. FTIR spectrophotometer was used to confirm the functional groups of the intermediate and dyes whereby the molecular mass of the synthesized coupling component was established. Other physical and chemical properties of the synthesized dyes such as UV-visible, melting points and percentage yield were determined. The exhaustion was very good on chrome tanned leather than vegetable tanned leather which may be attributed to chelating effect of chrome on leather and the high temperature of dyeing chrome tanned leather. The fastness properties (wash, light and perspiration) were good to very good on both vegetable tanned leather and chrome tanned leather respectively.

\section{References}

[1] Feeman, J.F. (1978) Leather Dyes. In: Venkataraman, K., Ed., The Chemistry of Synthesis Dyes, Vol. VIII, Academic Press, New York, Sanfrancisco, London, 39-41.

[2] Klaus, H. (2003) Industrial Dyes Chemistry, Properties, Applications. Wiley-VCH Verlag GmbH \& Co. KGaA, Weinheim.

[3] Carugo, O., Djinović, K., Rizzi, M. and Castellani, C.B. (1991) Studies on Metal Complexes of Ortho-Quinone Monooximes. Part 9. Analysis of the Charge Distribution within the o-Quinone Monooxime Ligands through Crystallographic Data. Journal of the Chemical Society, Dalton Transactions, 55, 1255-1258. http://dx.doi.org/10.1039/dt9910001255

[4] Sudershan, L. and Srivastava, S.N. (1967) Journal of Chemical Education, 44, 482.

[5] Baluch, D., Charalambous, J. and Haines, L.I.B. (1988) Manganese Complexes of 1,2-Naphthoquinone Mono-Oximes (2-Nitrosophenols) as Catalysts for Alkene Epoxidation. Journal of the Chemical Society, Chemical Communications, 17, 1178-1179. http://dx.doi.org/10.1039/c39880001178

[6] Verdoorn, T.A., Johansen, T.H., Drejer, J. and Nielsen, E.O. (1994) Selective Block of Recombinant Glur6 Receptors by NS-102, a Novel Non-NMDA Receptor Antagonist. European Journal of Pharmacology: Molecular Pharmacology, 269, 43-49. http://dx.doi.org/10.1016/0922-4106(94)90024-8

[7] Castaldi, G., Allegrini, P., Fusco, R., Longo, L. and Malatesta, V.J. (1991) New Thermo and Photochromic 10-Methylspiro\{Dibenzo[b,f][1,4]Oxazepino-11,3'-3H-Naphtho[2,1-b]-1,4-Oxazine\}. Journal of the Chemical Society, Chemical Communications, 18, 1257-1258. http://dx.doi.org/10.1039/c39910001257

[8] Yakubu, M.K. (2000) Synthesis and Dyeing Properties of Metallisable and Nonmetallisable Acid Dyes. Unpublished Thesis Work, Department of Textile Science and Technology, Ahmadu Bello University, Zaria.

[9] Society of Leather Technologist and Chemists (SLTC) (1996) Official Methods of Analysis. Northampton.

[10] Nkeonye, P.O. (1997) Fundamental Principle of Textile Dyeing, Printing and Finishing. Ahmadu Bello University Press Ltd., Zaria.

[11] Silverstein, R.M. and Webster, F.X. (1997) Spectrometric Identification of Organic Compounds. 6th Edition, John Wiley and Sons, Hoboken, 12-20.

[12] Ameuru, S.U. (2009) Synthesis, Characterization and the Dyeing Properties of Nitrosonaphthol Dyes on Tanned Leathers. Unpublished Thesis, Department of Textile Science and Technology, Ahmadu Bello University, Zaria.

[13] Evans, N.A. and Stapleton, I.W. (1978) Structural Factor Affecting the Light Fastness of Dyed Fibre. In: Venkataraman, K., Ed., The Chemistry of Synthetic Dyes, Vol. VIII, Academic Press, New York, Sanfrancisco, London, 227.

[14] Giles, C.H., Duff, D.G. and Sinclair, R.S. (1978) Relations between the Molecular Structures of Dyes and Their Technical Properties. In: Venkataraman K., Ed., The Chemistry of Synthetic Dyes, Vol. VIII, Ademic Press, New York, Sanfrancisco, London, 294. 